\title{
A ANÁLISE TEXTUAL DISCURSIVA ENQUANTO EXPERIÊNCIA ESTÉTICO-EDUCATIVA
}

\section{THE DISCURSIVE TEXTUAL ANALYSIS AS AN AESTHETIC- EDUCATIONAL EXPERIENCE}

\author{
Diana Paula Salomão de Freitas ${ }^{1}$
}

\begin{abstract}
Resumo: Tendo como foco a valorização da Análise Textual Discursiva (ATD) enquanto uma metodologia de caráter profundamente estético-educativo, destacamos a dimensão sensível e criativa no trabalho de pesquisa qualitativa, entendendo-a como fundamental no processo. A partir da descrição dos três momentos auto-organizados da metodologia criada por Moraes e Galiazzi, estabelecemos relações entre cada etapa da análise e aspectos estético-educativos experimentados nesses movimentos. Assim, são considerados o desenvolvimento da sensibilidade, da escuta e do olhar sensível, das emoções e sentimentos, do bom senso, da percepção subjetiva, da criatividade, intuição e imaginação dos pesquisadores envolvidos com ATD como elementos indispensáveis para o êxito pleno do trabalho de pesquisa.
\end{abstract}

Palavras-chave: Sensibilidade; Criatividade; Condição Humana; Estética; Sentido Estético.

Abstract: This paper focuses on the valorization of the Discursive Textual Analysis (DTA) as a fundamental aesthetic-educational methodology and highlights its sensitive and creative dimension in qualitative research. Based on the description of the three self-organized moments of the methodology created by Moraes and Galiazzi, relations were established between every stage of analysis and aestheticeducational aspects experienced in these movements. Thus, researchers' sensitivity, listening skills, sensitive look, emotions, feelings, common sense, subjective perception, creativity, intuition and imagination should be developed as essential elements to carry out successful research with the DTA.

Keywords: Sensitivity; Creativity; Human Condition; Aesthetics; Aesthetic Sense.

\section{Apresentação}

Neste ensaio, propomo-nos a compreender e a valorizar a Análise Textual Discursiva (ATD) como uma metodologia de pesquisa qualitativa de caráter profundamente estético-educativo, entendendo que isto é fundamental para que se atinja o máximo de seu potencial. Ao longo do texto, argumentamos que o envolvimento com a ATD, indo além da apropriação de uma profícua metodologia de análise de informações, tende a promover experiências e aprendizados de caráter estético. Defendemos, ainda, que a dimensão estética merece uma atenção mais consciente e valorizada nos movimentos de pesquisa, por ser decisiva para aprendizagens e possibilidades de realização mais plena dos sujeitos-pesquisadores em seus trabalhos.

\footnotetext{
${ }^{1}$ Doutora em Educação em Ciências pela Universidade Federal do Rio Grande (FURG). Docente da Faculdade de Educação da Universidade Federal de Pelotas (UFPel), Pelotas, Rio Grande do Sul, Brasil. E-mail: diana.freitas@ufpel.edu.br
} 
Muito mais abrangente que metodologias frias e racionalistas em que impera $o$ mecanicismo, a ATD é um convite ao estético, um aceno para desenvolvermos e refinarmos nossos sentidos e percepções, tornando-nos mais atentos e sensíveis aos aspectos dos fenômenos que buscamos compreender, de modo a refletir melhor sobre o investigado, assim como sobre o próprio movimento de investigação.

As experiências estéticas têm a ver com nossa percepção subjetiva da realidade, a partir de nosso envolvimento por inteiro. Assumindo-se que nas experiências incluindo os procedimentos de pesquisa - estão o corpo, a sensibilidade e os sentimentos, com o racional e a reflexão, a experiência estética está presente em todas as instâncias de nossas vidas, caracterizando o propriamente humano que acompanha nossas ações, nossos trabalhos e interações com os outros. "Ela nos fala de vida e morte, de alegria e tristeza, de sorte e fatalidade, de sonhos e desencantos, dialogando com a inteireza de nossa corporeidade" (DUARTE JÚNIOR, 2001, p.147). Relacionada à nossa capacidade de perceber e sentir, "inspirando" ou "conduzindo" o mundo para dentro (HILLMAN, 1993, p.17), a dimensão estética também está presente nas distintas relações experimentadas em um processo de pesquisa.

As vivências estéticas correspondem ao modo como as pessoas se relacionam entre si, com os fenômenos e com as coisas a partir de seus sentimentos, afetos e gostos. Tornam-se experiências estéticas ao serem percebidas e significadas enquanto emoções e sentimentos que nos passam, que nos acontecem, que nos tocam (BONDIA, 2002). Com a ATD, as experiências estéticas são consideradas educativas, na medida em que aprendemos a reconhecer que "emoção e prazer, angústias e medo, inseguranças e coragem para avançar sempre, são companheiros de todo o percurso" (MORAES; GALIAZZI, 2007, p.182-183). O colocar-se esteticamente nas pesquisas envolve a promoção de práticas de educação que levem o pesquisador, segundo Estévez, a

\footnotetext{
Soltar as amarras de seu espírito, ampliando suas necessidades mais além do puramente corporal; é revelar-lhe os segredos da beleza natural, das formas e volumes que povoam a natureza e o mundo das manifestações artísticas e do trabalho criador; é mostrar-lhe a fonte de sua beleza interna para enaltecer sua passagem pela vida; enfim, é entregar-lhe uma lanterna mágica para iluminar as zonas mais desamparadas de seu coração e deixá-lo andar, a conquistar um lugar próprio no pulsar alheio, e reconhecer seu 'eu' na alteridade (2009, p. 56).
}

A própria elaboração do presente texto carrega um forte aspecto emocional, pois remete (inclusive revisitando textos e conversas escritas) aos primeiros momentos de envolvimento desta autora com a ATD, ainda no ano de 2009, na Universidade Federal do Rio Grande, junto ao saudoso professor Roque Moraes. À época, por meio de 
estudos dialógicos, buscamos ampliar nossa compreensão da dimensão estética na educação e, por conseguinte, a valorização do sentido estético no trabalho de pesquisa, compreendendo-o como decisivo para aprendizagens significativas e possibilidades de realização mais plena dos próprios pesquisadores. Essas construções - revisitadas e ressignificadas - estão presentes neste texto.

Além desta breve apresentação, este texto está organizado em mais três partes. Na segunda parte, trazemos os motivos que nos mobilizaram a escrever sobre as experiências estético-educativas potencialmente vivenciadas quando nos envolvemos de “corpo e alma” com a ATD. Na sequência, então, a partir da descrição dos três momentos auto-organizados da metodologia criada por Moraes e Galiazzi (2007), construímos e evidenciamos relações entre cada etapa de análise e aspectos estéticoeducativos experimentados nos diferentes movimentos. Por fim, já na última parte deste ensaio, tecemos considerações finais sobre a importância de valorizar as emoções, o olhar e a escuta sensível, o bom senso, as percepções, a criatividade, a criação, a intuição e a imaginação enquanto sensibilidades desenvolvidas em experiências estético-educativas.

\section{Do racionalismo moderno utilitarista às experiências sensíveis nas pesquisas educacionais}

Valorizar o componente estético-educativo nas pesquisas, especialmente nas de abordagem qualitativa, implica assumir os pesquisadores em seus atributos humanos e sociais, seus sentimentos e afetividades. É preciso superar a visão utilitária exclusiva das interações e produções sociais e ampliar a valorização do ser, da condição humana na sua plenitude, em suas múltiplas relações com a realidade.

Tendo herdado o modo de pensar racionalista, tecnicista e utilitarista típico da modernidade ocidental, também a "ciência" e os seus procedimentos de pesquisa assumiram posturas dessa natureza, muitas vezes absolutizando aspectos ditos técnicos em detrimento de outros elementos da condição humana. Duarte Júnior (2009, p. 38) diz que, "enquanto uma atitude humana racional pressupõe um certo equilíbrio entre razão e sentimentos, o racionalismo diz respeito a uma submissão extrema e mesmo a uma repressão das manifestações do sentimento". Perceber e valorizar as experiências estético-educativas na pesquisa é um modo de realçar essa ação transformadora do ser e mobilizadora dos conhecimentos que vão sendo produzidos pela humanidade e de não a 
reduzir a um conjunto de ações mecânicas, realizadas e reproduzidas por autômatos que executam etapas, seguindo normas e desenvolvendo técnicas unicamente para satisfazer o fluxo de um sistema de produção, consumo e descarte de informações.

Na ciência moderna, caracterizada pelo paradigma dominante, segundo Santos (2008), os procedimentos precisam ser neutros, livres de sentimentos do pesquisador, isentos de seus valores pessoais e afetivos. Porém, isso tem se mostrado uma impossibilidade, algo simplesmente impraticável, pois o pesquisador entra em suas pesquisas sempre como pessoa em seu sentido completo, só podendo perceber os fenômenos de dentro deles e com total envolvimento. A ciência emergente nos novos paradigmas, segundo o mesmo autor (SANTOS, 2008), tem se aproximado da literatura e das artes, tendo com elas a imaginação criativa e a sensibilidade como elementos comuns. No mesmo sentido, nas palavras de Duarte Júnior,

A sensibilidade do indivíduo constitui, assim, o ponto de partida (e talvez, até
o de chegada) para nossas ações educacionais com vistas à construção de
uma sociedade mais justa e fraterna, que coloque a instrumentalidade da
ciência e da tecnologia como meio e não um fim em si mesma (2001, p. 139).

Ainda que nem sempre tenhamos consciência disto, juntamente com a lógica e a ética, a estética está presente em todas as nossas aprendizagens, nos modos de relacionarmo-nos. Nos dizeres de Montero et al.,

A atitude estética é um aspecto imprescindível da atividade laboral. É interna, em diferença do interesse material, constitui um estímulo interior emotivomoral do trabalho, funciona como elemento integrante da produção social e unifica os outros elementos em um sistema único, manifestando o seu sentido humano (1987, p.37-38).

O trabalho, juntamente com a natureza e a arte, constituem meios para o desenvolvimento de capacidades de relacionar-se esteticamente, dando caráter humano às relações. O pesquisador com bom desenvolvimento estético em seu trabalho de pesquisa sabe encantar-se com as próprias produções e descobertas, tornando o mundo um ambiente mais agradável para viver e para realizar-se. O trabalho, pela criatividade e pela capacidade de propiciar espaços de realização pessoal, constitui um importante elemento de formação estética.

No sentido de examinar algumas questões sobre o tema nos distintos movimentos minuciosos da Análise Textual Discursiva, que requerem atenção e rigorosidade dos pesquisadores, na próxima parte deste texto, estabelecemos um diálogo entre as construções de Moraes e Galiazzi (2007) sobre ATD e autores que abordam a educação estética, de forma a valorizar as relações estético-educativas que acontecem em todo o processo de análise. 


\section{As experiências estético-educativas nos movimentos da ATD}

\subsection{Escuta sensível, sensibilidade e bom senso para alimentar um caldeirão de ideias}

Ao optar pela metodologia qualitativa Análise Textual Discursiva, o pesquisador coloca-se em um processo integrado de análise e síntese, pela leitura rigorosa e aprofundada de um conjunto de materiais textuais, a fim de descrevê-los e interpretálos, "com a finalidade de produzir novas compreensões sobre os fenômenos e os discursos" (MORAES; GALIAZZI, 2007, p. 7). Com ATD, fazemos uso de textos, os quais devem ser apreciados pela "escuta sensível” do pesquisador (BARBIER, 2007, p.96-97; MORAES; GALIAZZI, 2007). Diferentemente de logo interpretar o que foi produzido, o pesquisador (ad)mira com sensibilidade e rigorosidade, no sentido de respeitar o que encontra nas produções textuais. Nos moldes do que afirma Duarte Júnior,

Sem dúvida, há um saber sensível, inelutável, primitivo, fundador de todos os demais conhecimentos, por mais abstratos que estes sejam; um saber direto, corporal, anterior às representações simbólicas que permitem os nossos processos de raciocínio e reflexão (2001, p 12).

É o desenvolvimento da sensibilidade que o pesquisador pode aguçar e aprimorar nesse momento com ATD. A sensibilidade, enquanto fato social, tem um importante reconhecimento no que foi denominado por Barbier (2007) como uma tendência emergente caracterizada como "novas ciências antropossociais". Também João Francisco Duarte Júnior destaca a consideração da Ciência com relação à observação atenta ao que poderia passar despercebido, para que se identifiquem procedimentos adequados para a construção de soluções dos problemas investigados.

\footnotetext{
A sensibilidade (auditiva, visual, gustativa, tátil e olfativa) aos detalhes e particularidades, ocultas aos insensíveis, afigura-se, portanto, como deflagradora de alguns outros processos mentais, dentre eles o pensamento e esse seu desenvolvimento mais rigoroso na forma de um raciocínio lógicoconceitual (DUARTE JÚNIOR, 2001, p. 185).
}

O desenvolvimento da sensibilidade é o que permite que o pesquisador compreenda e desfrute dos avanços em cada etapa da pesquisa. Também faz com que, em um sentido mais amplo, venha a contemplar a arte, a natureza e o seu próprio trabalho. Isto não para ser necessariamente um artista, nem para tocar um instrumento musical, mas para ser capaz de projetar sua sensibilidade (estética) na sua atividade vital (ESTÉVEZ, 2008). 
Na ATD, a escuta e o olhar sensíveis são recomendados inicialmente para os textos que constituirão o corpus de análise do pesquisador. Assumidos como produções linguísticas, referentes ao que se pretende melhor compreender, originadas em um tempo e contexto específicos, os textos, para Moraes e Galiazzi,

São vistos como produções que expressam discursos sobre diferentes fenômenos e que podem ser lidos, descritos e interpretados, correspondendo a uma multiplicidade de sentidos que a partir deles podem ser construídos. Os documentos textuais da análise constituem significantes a partir dos quais são construídos significados relativos aos fenômenos investigados (MORAES; GALIAZZI, 2007, p.16).

"Porta de entrada das sensações", a sensibilidade humana está associada à nossa permanente abertura ao mundo, conectando-nos ao que se passa em nosso entorno (OSTROWER, 2001). Relaciona-se à nossa disposição para apreender os sinais emitidos pelas coisas e por nós mesmos (ESTÉVEZ, 2014). Com “escuta sensível”, pesquisadores podem interagir melhor com os registros escritos a serem analisados, de modo a mergulharem mais intensamente no fenômeno que pretendem compreender, realizando uma leitura a partir da perspectiva do outro, em um esforço de "colocar entre parênteses" suas próprias ideias e teorias (MORAES, 2003). Em nossa compreensão, isso vai ao encontro do que Munhoz e Zanella consideraram como estabelecimento de relações estéticas com o mundo. "Seria algo como olhar o igual de modo diferente, e então alcançar o que está ali e que é oculto e evidente ao mesmo tempo, mas cuja cotidianidade nos cega" (MUNHOZ; ZANELLA, 2008, p. 392).

Os registros escritos que constituem o corpus de análise da pesquisa são as produções textuais referentes ao que se pretende compreender. Podem ser relatos pessoais escritos, observações de situações registradas em diários de bordo, transcrições de questionários ou de entrevistas, bem como reportagens e documentos. Também as ideias e compreensões do pesquisador sobre o que se investiga precisam integrar o corpus de análise. "Assim o movimento da escrita reconstrutiva inicia-se com um esforço do autor em expressar seus próprios entendimentos sobre os temas que pretende reconstruir" (MORAES; GALIAZZI, 2007, p.198).

Para Moraes e Galiazzi, "é importante entender a escrita como outro modo de pensamento, ferramenta do pensar que ao mesmo tempo em que procura comunicar algo possibilita uma evolução dos modos de pensar de quem nela se envolve" (MORAES; GALIAZZI, 2007, p. 195). Os autores destacam a função epistêmica da escrita e encorajam os pesquisadores a expressarem suas ideias acerca do que querem investigar. Em nosso entendimento, estimulam relações estéticas entre o pesquisador-autor e as 
atividades de escrever e ler, produzindo cultura, "pois, veiculam sentidos culturalmente construídos e compartilhados e, ao mesmo tempo possibilitam, em razão de seu caráter polissêmico, a produção de novos sentidos" (MUNHOZ; ZANELLA, 2008, p. 289).

Escrevendo, o pesquisador vai se tornando capaz de ler além de frases no texto e passa a perceber o que escreve enquanto produção textual inserida em um contexto histórico-cultural específico, mobilizando memórias, sensações e afetos, e promovendo relações estéticas com o texto. "A linguagem escrita possibilita ao ser humano inscrever no tempo a sua própria história e reler, tantas vezes quantas se fizerem necessárias, o que escreveu para então (re)criá-la” (MUNHOZ; ZANELLA, 2008, p. 288).

A definição da dimensão do corpus de análise envolve, ainda, o bom senso do pesquisador na experiência estética com ATD. Caracterizado por Moraes e Galiazzi (2007) como o "alimentar de um caldeirão de ideias", estabelecer até quando produzir dados para a pesquisa implica o exercício de perceber quando os temas ou fenômenos estão suficientemente explicitados. Nisto, pesquisadores colocam em prática a capacidade de indagar, comparar, duvidar, aferir, expressar curiosidades e, dessa forma, desenvolver criticidade (FREIRE, 2009). O bom senso para definir a extensão do corpus de análise é importante, visto que "a tempestade produz muitos clarões, novas compreensões emergentes que requerem atenção e trabalho para sua explicitação" (MORAES; GALIAZZI, 2007, p. 200).

\subsection{Percepções e sensibilidades na desmontagem dos textos}

Reunidos os registros que serão analisados e definido, assim, o corpus de análise da pesquisa, inicia-se o momento da ATD denominado desmontagem de textos. Trata-se de desorganizar as produções textuais do que se pretende compreender, buscando por sentenças/fragmentos que mostram significados do que se quer reconstruir, com foco no que significam na totalidade do texto e no atual contexto (BICUDO, 2011). É o momento em que, mais uma vez, se investe na escuta sensível (BARBIER, 2007) para perceber o que unidades de significado mostram acerca do fenômeno investigado, mas sem direcionamentos, deixando que livremente se manifestem (MORAES; GALIAZZI, 2007). As unidades de significado retiradas do texto revelam a intencionalidade do pesquisador.

Mais uma vez, o pesquisador experimenta múltiplas sensibilidades e formas de expressão do fenômeno investigado. Enquanto experiência estética, na desmontagem 
dos textos, o desenvolvimento da sensibilidade está presente na forma como as unidades de significado chegam aos sentidos do pesquisador e neles penetram - uma experiência estética, no sentido trazido por James Hillman. Em seus dizeres: "a respiração entrecortada, ‘a-ah', o ‘uhh' da respiração diante da surpresa, do susto, do espanto, uma reação estética à imagem (eidolon) apresentada" (HILLMAN, 1993, p.17). É muito importante que se estimule, nos pesquisadores que vivenciam a ATD, a capacidade de surpreender-se, de (ad)mirar-se e de espantar-se diante das informações analisadas.

A busca pelas unidades de significado na desordem dos textos é o processo de unitarização, que envolve também uma organização para que uma nova ordem seja estabelecida pelas novas compreensões do assunto investigado. Moraes e Galiazzi (2007, p. 21) afirmam que "exercitar uma leitura aprofundada significa explorar uma diversidade de significados que podem ser construídos a partir de um conjunto de significantes". Em nossa compreensão, a estética, nesse momento, pode ser experimentada quando o pesquisador capta o sentido nas unidades analisadas, sem significação utilitária direta (MONTERO et al., 1987), mas buscando pela essência do que expressam.

Após desconstruir o texto, o pesquisador tem nova oportunidade de imergir no fenômeno, selecionando palavras-chave retiradas literalmente das unidades de significado e com elas construindo enunciados descritivos (ARIZA et al., 2015). Tratase, pois, de elaborar frases com as palavras-chave que descrevem os fragmentos de texto com sentido em si, para que não se tenha que lidar com todas as sentenças encontradas, na continuidade dos movimentos de análise. Moraes e Galiazzi (2007) orientam que seja atribuído um código às unidades de significados recortadas do corpus, a fim de localizálas posteriormente e assim não se perder de vista o todo.

Elaborando enunciados descritivos das unidades de significado retiradas do corpus de análise e atribuindo-lhes depois um código, pesquisadores exercitam a sensibilidade em um complexo tecido de percepções. Múltiplas experiências sensoriais, indo além da pesquisa, são fundamentais para aguçar a percepção do pesquisador, porque a percepção vai delimitar o que ele será capaz de sentir e compreender do que investiga. A percepção "articula o mundo que nos atinge, o mundo que chegamos a conhecer e dentro do qual nós nos conhecemos. Articula o nosso ser dentro do não-ser" (OSTROWER, 2001, p.13). Nesse sentido, além de envolver-se intensamente com sua pesquisa, é importante que o pesquisador tenha momentos de lazer, realize passeios, desfrute da arte em suas linguagens musicais, visuais, teatrais e com a dança, deleite-se 
com paisagens naturais e urbanas, admirando o pôr-do-sol, o canto dos pássaros, as cores do arco-íris, na convivência com as pessoas que ama (ESTEVEZ, 2008).

\subsection{Criatividade, intuição e imaginação para saborear o caldeirão de ideias}

Partindo da metáfora do caldeirão de ideias, o próximo momento de experiências estético-educativas com ATD foi denominado por Moraes e Galiazzi (2007) como estabelecimento de relações ou categorização, associando-o às formas de saborear o caldeirão. Nesse momento, intensas experiências estético-educativas acontecem, em virtude de que a estética existe somente em relação, ou seja, um objeto, uma pessoa, um fenômeno, são potencialmente estéticos, tornando-se estéticos quando notados, percebidos, contemplados. Também o "sujeito contemplador" comporta-se esteticamente quando entra em relação com um objeto ou com outro sujeito. Nos dizeres de Adolfo Sanchéz Vasquez, "o que existe, na verdade, é a experiência que o objeto provoca ou o estado de atitude engendrada na (e não antes da) relação estética, concreta, singular, com esse objeto" (1999, p.108).

$\mathrm{Na}$ categorização, é realizado um exercício de comparação constante entre unidades de significado, buscando-se agrupar aquelas com sentidos semelhantes. É um convite para o pesquisador experienciar aspectos emocionais implicados nas construções conceituais em curso (ESTEVEZ ALVAREZ, 2017), pela sensibilidade de associar distintas ideias, conceitos e reflexões advindos do fenômeno.

A categorização é um momento central no processo da ATD, segundo Moraes e Galiazzi (2007). Ao aproximarem-se as unidades de significado por semelhanças, surgem conjuntos de temáticas pertinentes ao tema de pesquisa, de forma espontânea, auto-organizada e intuitiva. Entende-se espontâneo, aqui, no sentido trazido por Ostrower, de que "nada tem a ver com ser independente de influências. Isso em si é impossível ao ser humano. Ser espontâneo apenas significa ser coerente consigo mesmo" (2001, p. 147).

Quanto maior a imersão do pesquisador no tema, melhor ele percebe os aspectos inesperados relacionados ao investigado. Por esse motivo, a metodologia demanda esforço, dedicação, criatividade, paciência e o exercício de lidar com a insegurança. $\mathrm{O}$ ato criativo é uma autêntica experiência estética nos processos de pesquisa, nos modos trazidos por Ostrower: "Seja qual for a área de atuação, a criatividade se elabora em nossa capacidade de selecionar, relacionar e integrar os dados do mundo externo e 
interno, de transformá-los com o propósito de encaminhá-los para um sentido mais completo" (2001, p.69). Com Análise Textual Discursiva, o exercício da criatividade, enquanto processo humano existencial, consiste em dar forma a "algo novo", de estabelecer novas coerências entre os aspectos envolvidos nos fenômenos e nos discursos investigados.

Novas organizações emergem do corpus de análise, mas a decisão sobre o que aprofundar cabe ao pesquisador, a partir do que conseguirá captar e expressar. Diferentes níveis de categorias vão surgindo do movimento de aproximação por semelhanças das unidades de significado. Primeiramente, reúnem-se as unidades de significado com elementos parecidos, nas denominadas categorias iniciais. Em seguida, estas categorias são reagrupadas por proximidade, de maneira a serem estabelecidas categorias intermediárias, que, novamente aproximadas pela busca de correlações ainda mais achegadas, alcançam categorias finais.

"O próprio processo de categorização é modo de intensificar a impregnação nos materiais" (MORAES; GALIAZZI, 2007, p. 205). Nesse momento, diferentes modos de categorizar os elementos que constituirão o novo emergente podem ser assumidos pelo pesquisador. Moraes e Galiazzi (2007) pontuam-nos como: i) dedutivo, quando as categorias são previamente construídas antes de se apreciarem as informações da pesquisa e, por isso, são denominadas a priori; ii) indutivo, quando, a partir das unidades de significado, se constroem as categorias e, por isso, estas são denominadas emergentes; iii) análise mista, quando o pesquisador parte de categorias definidas $a$ priori e, no decorrer do processo de análise, também permite a emergência de outras categorias; iv) intuitivo, modo em que a intuição guia o processo, a partir de insights do pesquisador, que então chegará a um conjunto de categorias.

Na base dos processos de criação, juntamente com a percepção, Ostrower (2001) e Alvarez Estevez (2017) consideraram a intuição como um dos mais importantes modos cognitivos do homem. "Ambas, intuição e percepção, são modos de conhecimento, vias de buscar certas ordenações e certos significados" (OSTROWER, 2001, p. 57). A intuição permite lidar com situações novas e inesperadas, de forma imediata. Permite agir espontaneamente, visualizando e internalizando o acontecimento dos fenômenos, comparando e permitindo compreender seus aspectos. "Intuindo-se, procura-se estabelecer relacionamentos significativos - significativos para uma matéria e para nós" (OSTROWER, 2001, p. 69). 
Com envolvimentos emocionais e afetivos, a imaginação, em sua estreita relação com a liberdade, a intuição e a criatividade, é elemento de formação da consciência e de recriação de nossos mundos. A imaginação "possibilita que a pessoa amplie seu conhecimento, pois permite que esta se aproprie de múltiplas experiências suas e alheias e as transcenda, ao ser capaz de imaginar o que nunca viu" (MUNHOZ; ZANELLA, 2008, p. 290-291). Saberes sensíveis, como é a imaginação, conforme frisado por Duarte Júnior “[...] consiste, pois, numa das mais eficazes ferramentas de que dispõe a humanidade para a criação do saber" (2001, p. 135).

Com isso, compreendemos que, no processo de categorização com ATD, intuir não acontece apenas por noções intelectuais, mas, de modo mais amplo, também pelas experiências anteriores, vividas "de corpo inteiro". O pesquisador relaciona as unidades de significado, agrupando-as em conjuntos que unificam aspectos do que está investigando. Ainda na categorização, o pesquisador vai imaginando e visualizando como ordenará as categorias encontradas, em um texto no qual reconstruirá os discursos sobre o fenômeno que busca compreender, ou seja, vai tornando visível a concretização do metatexto, o que descreveremos a seguir.

\subsection{Chegando ao metatexto: processo de recriação concreto-sensível}

O último momento da ATD foi denominado por Moraes e Galiazzi como captação do emergente, em que é evidenciada a construção do que o pesquisador elaborou na pesquisa. $\mathrm{O}$ metatexto resultante do trabalho do pesquisador configura-se como um processo de criação no qual se incorporam "objetivação e plasmação de finalidades, ideias ou sentimentos humanos num objeto material, concreto-sensível" (SÁNCHEZ VÁZQUEZ, 1968, p. 69). O momento de elaboração do metatexto, segundo Moraes e Galiazzi, é a “[...] expressão por meio das principais ideias emergentes das análises e apresentação dos argumentos construídos pelo pesquisador em sua investigação, capaz de comunicar a outros as novas compreensões atingidas" (MORAES; GALIAZZI, 2007, p. 94).

Nesse processo, são manifestadas as novas compreensões do pesquisador, ancoradas em diálogos teóricos e empíricos. É o momento de produção de um texto sobre os textos analisados, por isso um metatexto, com ordenação dos parágrafos e interlocução teórica. A captação do emergente é o momento de o pesquisador vivenciar o "ressurgir da Fênix" - metáfora usada por Moraes e Galiazzi para ilustrar o processo 
de captação do novo emergente, considerando a ave mitológica. Os autores destacam que a ave Fênix sempre ressurge das suas cinzas, de sua constituição original; segundo eles, "isso ocorre também com os conhecimentos dos sujeitos que para ressurgirem exigem envolver-se em movimentos desconstrutivos-reconstrutivos capazes de propiciarem constantemente a emergência do novo" (MORAES; GALIAZZI, 2007, p. 215).

Nesse momento, convidam-se outros sujeitos envolvidos com o tema investigado "a título da contribuição que se espera possam dar [...] pelo aporte teórico que se requer capaz de ampliar os horizontes do tratamento do tema" (MARQUES, 2008, p. 101). Seriam outros estudiosos que, pela mesma base epistemológica do pesquisador, já teorizaram sobre o tema, além das produções empíricas de outros sujeitos que colaboraram com a pesquisa. "Isso não apenas evidencia a dialogicidade das produções, dando créditos aos interlocutores que participaram de sua criação, mas também amplia as possibilidades de aceitação das reconstruções por comunidades mais amplas de interlocutores críticos" (MORAES; GALIAZZI, 2007, p. 209). No convite a outras vozes para que o pesquisador se aproprie de novos modos discursivos acerca do que investigou, o ato criativo, nesse momento da análise, expressa-se no encontro com o outro. "No indivíduo confrontam-se, por assim dizer, dois polos de uma mesma relação: a sua criatividade que representa as potencialidades de um ser único, e sua criação que será a realização dessas potencialidades já dentro do quadro de determinada cultura" (OSTROWER, 2001, p. 5).

Nessa fase, momento em que o pesquisador decide não trazer mais elementos e se coloca a escrever, a ler e novamente a escrever recursivamente sobre o escopo construído até o momento, chega-se a uma etapa da ATD na qual Moraes e Galiazzi (2007) incentivam a leitura crítica e mesmo o diálogo entre pares, convidando colegas para ajudar na validação dos argumentos construídos. Para os autores, “[...] a clareza e qualidade de um texto vai se concretizando ao longo de um intermitente processo de reescritas, revelando-se em diálogos cada vez mais claros, mostrando uma compreensão gradativamente mais elaborada do autor sobre os temas que aborda" (MORAES; GALIAZZI, 2007, p. 197). Pela leitura de colaboradores, novos questionamentos podem ajudar a esclarecer melhor eventuais lacunas na compreensão dos fenômenos ou mesmo a produzir novos argumentos e teses trazidos no metatexto.

Cabe ainda destacar que, no envolvimento com a ATD, somos inundados por diferentes emoções, e a insegurança é uma delas. Juntamente com a segurança, o 
contentamento e a alegria sentidos no decorrer do desenvolvimento e conclusão de cada etapa da pesquisa, é importante reconhecer e aprender a lidar com as emoções de insegurança, descontentamento e tristeza, também sentidas. $O$ texto final é resultado de um processo de trabalho constituído pelas escritas, leituras, releituras e reescritas que o precederam e permeado por aquelas emoções. De uma maneira mais intensa, dizemos que a versão acabada advém de lutas e anseios íntimos, justamente porque "o final é indissolúvel dos momentos anteriores porque consequência necessária" (OSTROWER, 2001, p. 72).

Diferentemente da ideia de que as relações são estabelecidas por momentos de inspiração, nossas aprendizagens e os avanços na construção da autoria acontecem na tensão entre o estabelecido antes - seja por nós mesmos, seja por outros - e o novo emergente. No esforço de trabalhar com envolvimento nas informações produzidas é que podem surgir compreensões mais elaboradas do que se investiga, sem que, contudo, se deixe de sentir as agruras, inseguranças, alegrias, sensações de êxito e segurança, enquanto emoções naturalmente presentes no processo. Sobre isso, compartilhamos a seguir uma interessante reflexão de Ostrower.

\begin{abstract}
Momento inspirado, mostra-nos o quanto os momentos anteriores também foram inspirados; talvez até mesmo certos erros no trabalho foram inspirados. Pensar na inspiração como instante aleatório que venha a desencadear um processo criativo é uma noção romântica. Não há como a inspiração possa ocorrer desvinculada de uma elaboração já em curso, de um engajamento constante e total, embora não consciente (OSTROWER, 2001, p.72- 73).
\end{abstract}

São o constante envolvimento com a pesquisa e a permanente retomada do sentido do trabalho, do propósito inicial, da curiosidade que nos levou à pesquisa, o que nos garantirá a segurança de nos movimentarmos em mundos já dominados e em espaços de inovação e criatividade, movidos pela imaginação. Isso é o que nos permite explorar mundos novos, geralmente inseguros, onde nossos movimentos são sempre imprecisos, ainda que desafiadores (DUARTE JÚNIOR, 2001).

Com relação ao constante estado de tensão emocional experimentado nas produções criativas, tal como são o resultado e o processo como um todo experimentados por meio da ATD na pesquisa com abordagem qualitativa, acolhemos as colocações de Ostrower (2001) quando diz que:

Em qualquer campo de criação, o indivíduo teria que ser capaz de sustentar um estado de tensão, de concentração espiritual e emocional, de conscientização de si, de um longo esforço de produção, por semanas, meses, anos, pelo tempo que possa durar um trabalho. Durante esse tempo, nos diferentes planos do viver, talvez no trabalho profissional também, hão de ocorrer os incidentes mais variados, sucessos, fracassos, alegrias, tristezas, 
amor, nascimentos, mortes. Produzirão emoções e pensamentos diversos, possivelmente até contraditórios (OSTROWER, 2001, p.73-74).

Esse permanente estado de tensão emocional é também experiência estéticoeducativa aos pesquisadores pelos diversos sentidos e significados que se propagam além dos estímulos elementares advindos dos momentos de análise, porque dialoga com o pesquisador por inteiro. Para lidar com essa tensão e renovarmo-nos, Ostrower convida-nos a concentrarmo-nos na qualidade de nosso engajamento interno para alcançarmos e mantermos nossa atenção no sentido original do que nos levou à pesquisa (OSTROWER, 2001). Encerrando esta parte do texto, o relato de uma mestranda que percorreu os caminhos da Análise Textual Discursiva, trazido por Moraes e Galiazzi, expressa essa profunda sensibilização:

Com isso, aquela sensação inicial cedeu espaço para uma outra percepção: a de que o jogo com as palavras constitui um processo altamente criativo que, quando bem processado e, se bem sustentado teoricamente, é capaz de transformar palavras soltas em sonoro poema (2007, p. 181-182).

\section{Considerações finais}

Ao longo das diferentes e complementares etapas da ATD, descritas anteriormente em interlocução com teóricos, valorizamos a escuta e o olhar sensível, o bom senso, as percepções, a criatividade, a criação, a intuição, a imaginação e as emoções, enquanto sensibilidades desenvolvidas em experiências estéticas que acontecem no processo de análise. Mostramos o quão importantes são essas atribuições no trabalho de pesquisa qualitativa e na própria vida como um todo do sujeitopesquisador que se envolve com ATD.

Destacamos que, por meio da ATD, os pesquisadores vivenciam experiências estético-educativas, mais complexas do que simples experiências sensoriais, por carregarem sentidos e significados além dos estímulos elementares. Durante a pesquisa, o exercício do bom senso vai advertindo e exigindo posicionamentos diante dos fatos. Esse modo de perceber a metodologia e de nela se colocar é de suma importância, considerando-se o objetivo fim da ciência, de "traduzir-se em sabedoria de vida" (SANTOS, 2008, p. 91).

Nesse sentido, faz-se necessário valorizarmos a sensibilidade nas análises das pesquisas produtoras dos conhecimentos, como um esforço para harmonizar pesquisadores com seu entorno, com os outros, com a natureza não humana, assim como com sua consciência, com seu corpo e com sua conduta. Mesmo que, por óbvio, a 
rigorosidade técnica e conceitual seja de grande relevância nas pesquisas, é importante compreender que, sem a liberdade de criação, sem a imaginação e sem a intuição, não conseguiremos vislumbrar e produzir mundos humanos alternativos.

Quando temos uma consciência estética desenvolvida, operamos com criatividade, bom senso, intuição e imaginação. Quando esses elementos são valorizados em nossos pensamentos e práticas, temos condições de viver de forma mais plena, com satisfação e alegria em nossas realizações, ou mesmo de buscar superação e inventividade nos momentos e situações adversas. Quando somos imaginativos, intuitivos e criativos, o somos com todo o corpo, incluindo nossos sentidos, a partir de uma mente flexível que se autoriza a operar com liberdade em relação a conhecimentos, atitudes e valores já estabelecidos. Isso também inclui a rigorosidade, no sentido de respeitar as próprias convicções, assim como as construções estabelecidas por teóricos com quem se define dialogar.

Ao apresentarmos e discutirmos alguns dos sentidos e significados de uma experiência estético-educativa por meio da ATD e em todos os momentos do trabalho acadêmico, objetivamos, em verdade, encorajar pesquisadores para que conscientemente impregnem seus projetos pessoais e de pesquisa (sociais) com um sentido estético. Que a capacidade de sentir, de emocionar e de emocionar-se, de sonhar, imaginar, criar e dar um sentido profundamente humano - tanto em trabalhos de pesquisa qualitativa, quanto em todas as áreas -, ocupe de vez o lugar da indiferença, do anestesiamento, do mecanicismo e do racionalismo moderno instrumental. Trata-se de um verdadeiro resgate da condição estética das pessoas, condição esta tão reprimida no modelo de pesquisa racionalista, moderno e cartesiano e em suas relações utilitárias, tão propagadas na modernidade.

\section{Referências}

ARIZA, L. G. A. et al. Relaciones entre el Análisis Textual Discursivo y el software Atlas.Ti en Interacciones Dialógicas. Campo Abierto. Revista de Educación, Badajoz, v. 34, n. 2, p. 105124, dez. 2015.

BARBIER, R. A Pesquisa - Ação. Trad. Lucie Didio. 8. ed. Brasília: Liber Livro Editora, 2007.

BICUDO, M. A. V. Aspectos da pesquisa qualitativa efetuada em uma abordagem fenomenológica. In: BICUDO, M. A. V. (org.). Pesquisa qualitativa segundo uma visão

fenomenológica. São Paulo: Editora Cortez, 2011. p. 29-40. 
BONDIA, J. L. Notas sobre a experiência e o saber de experiência. Rev. Bras. Educ., Rio de Janeiro, n. 19, p. 20-28, jan./abr. 2002. Disponível em: https://doi.org/10.1590/S141324782002000100003. Acesso em: 24 nov. 2020.

DUARTE JÚNIOR, J. F. Sentido dos Sentidos: a educação (do) sensível. 3.ed. Curitiba: Criar, 2001

DUARTE JÚNIOR, J. F. O que é beleza? São Paulo: Brasiliense, 2a . reimpressão da 3. ed., 2009.

ESTÉVEZ, P. R. Los colores del arco iris. La Habana: Editorial Pueblo y Educación, 2008.

ESTÉVEZ, P. R. A alternativa estética na educação. Rio Grande: Ed. Da FURG, 2009

ESTÉVEZ, P. R. Enseñar a sentir. Educación, La Habana, v.1, n.143, p.33-40, maio/ago. 2014.

ESTEVEZ ALVAREZ, L. La educación estético-ambiental en la formación de educadores(as). 2017. Tese (Doutorado em Educação Ambiental) - Instituto de Educação, Universidade Federal de Rio Grande, Rio Grande, 2017.

FREIRE, P. Pedagogia da Autonomia: saberes necessários à prática educativa. 40. reimpressão. São Paulo: Paz e Terra, 2009.

HILLMAN, J. Cidade \& Alma. Trad. Gustavo Barcellos e Lúcia Rosenberg. São Paulo: Studio Nobel, 1993

MARQUES, M. O. Escrever é preciso: o princípio da pesquisa. Petrópolis: Vozes, 2008.

MONTERO, G. et al. La educación estética del hombre nuevo. La Habana: Editorial de Ciencias Sociales, 1987.

MORAES, R. Uma tempestade de luz: a compreensão possibilitada pela análise textual discursiva. Ciênc. educ., Bauru, v. 9, n. 2, p. 191-211, 2003. Disponível em:

http://www.scielo.br/scielo.php?script=sci_arttext\&pid=S1516-

$73132003000200004 \& \operatorname{lng}=$ es\&nrm=iso. Acesso em: 31 out. 2020.

MORAES, R.; GALIAZZI, M. do C. Análise Textual Discursiva. Ijuí: Ed. Unijuí,2007.

MUNHOZ, S. C. D.; ZANELLA, A. V. Linguagem escrita e relações estéticas: algumas considerações. Psicologia em Estudo, Maringá, v.13, n.2, p.287-295, abr./jun. 2008. Disponível em: http://www.scielo.br/pdf/pe/v13n2/a11v13n2.pdf. Acesso em: 18 out. 2020.

OSTROWER, F. Criatividade e processos de criação. 15. ed. Petrópolis: Editora Vozes Ltda, 2001. Disponível em: https://pt.scribd.com/doc/115041658/LIVRO-CRIATIVIDADE-EPROCESSOS-DE-CRIACAO-Fayga-Ostrower. Acesso em: 30 out. 2020.

SANTOS, B. de S. Um discurso sobre as ciências. 5. ed. São Paulo: Cortez, 2008.

SÁNCHEZ VÁZQUEZ, A. Convite à Estética. Trad. Gilson Batista Soares. Rio de Janeiro: Civilização Brasileira, 1999.

SÁNCHEZ VÁZQUEZ, A. As idéias estéticas de Marx. São Paulo: Editora Paz e Terra LTDA, 1968. 